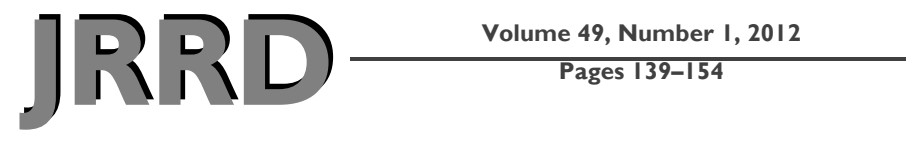

\title{
Measurement of social participation outcomes in rehabilitation of veterans with traumatic brain injury
}

William Stiers, PhD; ${ }^{*}$ Noelle Carlozzi, PhD $;^{2}$ Alison Cernich, PhD ${ }^{3}$ Craig Velozo, PhD; ${ }^{4}$ Theresa Pape, DrPH; ${ }^{5}$ Tessa Hart, PhD; ${ }^{6}$ Suzy Gulliver, PhD; ${ }^{7}$ Margaret Rogers, PhD; ${ }^{8}$ Edgar Villarreal, MS; ${ }^{9}$ Shalanda Gordon, PhD; ${ }^{10}$ Wayne Gordon, PhD; ${ }^{11}$ Gale Whiteneck, PhD ${ }^{12}$

${ }^{1}$ Department of Physical Medicine and Rehabilitation, Johns Hopkins University School of Medicine, Baltimore, MD;

${ }^{2}$ Kessler Foundation Research Center, West Orange, NJ; and Department of Physical Medicine and Rehabilitation, New Jersey Medical School, University of Medicine \& Dentistry of New Jersey, Newark, NJ; ${ }^{3}$ Neuropsychology, Department of Veterans Affairs (VA) Maryland Health Care System, Baltimore, MD; and Departments of Neurology and Psychiatry, University of Maryland School of Medicine, Baltimore, MD; ${ }^{4}$ North Florida/South Georgia Veterans Health System, Gainesville, FL; and Department of Occupational Therapy, University of Florida, Gainesville, FL; ${ }^{5}$ Edward Hines, Jr. VA Hospital, Hines, IL; and Feinberg School of Medicine, Northwestern University, Chicago, IL; ${ }^{6}$ Moss Rehabilitation Research Institute, Elkins Park, PA; and Department of Psychiatry, Einstein Medical Center, Einstein Healthcare Network, Philadelphia, PA; ${ }^{7}$ Center of Excellence for Research on Returning War Veterans, Central Texas Veterans Health Care System, Waco VA Medical Center, Waco, TX; and College of Medicine, Texas A\&M Health Science Center, Bryan, $\mathrm{TX} ;{ }^{8}$ American Speech-Language-Hearing Association, Rockville, MD; ${ }^{9}$ VA Eastern Colorado Health Care System, Denver, CO; ${ }^{10}$ Austin Outpatient Clinic, Central Texas Veterans Health Care System, Austin, TX; and St. Phillip's College, San Antonio, TX; ${ }^{11}$ Department of Rehabilitation Medicine, Mt. Sanai School of Medicine, New York, NY; ${ }^{12}$ Craig Hospital, Englewood, $\mathrm{CO}$

Abstract-Traumatic brain injury (TBI) is a significant concern in the veteran population, and the Department of Veteran Affairs (VA) has devoted substantial healthcare resources to the rehabilitation of veterans with TBI. Evaluating the outcomes of these rehabilitation activities requires measuring whether they meaningfully improve veterans' lives, especially with regard to community and vocational participation, which are strongly linked to perceived quality of life. In January 2010, the VA Rehabilitation Research and Development Service convened an invitational conference focused on outcome measurement in rehabilitation with a specific focus on veterans' community and vocational participation. This article reports on the working group, addressing the issues of conceptualizing and operationalizing such participation outcome measures for veterans with TBI; we discuss conceptual models of participation, review participation subdomains and their instruments of measurement, and identify current research issues and needs. Two avenues are identified for advancing participation measurement in veterans with TBI. First, we describe suggestions to facilitate the immediate implementation of participation measurement into TBI clinical practice and rehabilitation (cont) $\overline{\text { Abbreviations: } \text { CAT }}=$ computer-adaptive testing; CHART $=$ Craig Handicap Assessment and Reporting Technique; CIQ = Community Integration Questionnaire; FDA = Food and Drug Administration; ICF = International Classification of Functioning, Disability, and Health; M2PI = Mayo-Portland Adaptability Inventory 8-Item Participation Index; MPAI = MayoPortland Adaptability Inventory; NIDRR = National Institute on Disability and Rehabilitation Research; NIH = National Institutes of Health; PART = Participation Assessed with Recombined Tools; PDA = personal digital assistant; Polytrauma-QOL = Polytrauma-Quality of Life; POPS = Participation Objective-Participation Subjective Scale; PTSD = posttraumatic stress disorder; RR\&D = Rehabilitation Research and Development; TBI = traumatic brain injury; TBI-QOL = TBI-Quality of Life; VA = Department of Veterans Affairs.

* Address all correspondence to William Stiers, PhD; Johns Hopkins University School of Medicine, Department of Physical Medicine and Rehabilitation, 5601 Loch Raven Blvd, Suite 406, Baltimore, MD 21239; 443-444-4700; fax: 443-444-4770. Email: wstiers1@jhmi.edu

http://dx.doi.org/10.1682/JRRD.2010.07.0131 
(cont) Abstract - research within the VA healthcare system. Second, we describe recommendations for future VA research funding initiatives specific to improving the measurement of participation in veterans with TBI.

Key words: clinical practice, measurement, outcomes, participation, rehabilitation, research, social participation, traumatic brain injury, VA, veterans.

\section{INTRODUCTION}

Traumatic brain injury (TBI) is a problem of great concern for the veteran population, and the Department of Veteran Affairs (VA) has devoted significant healthcare resources to the rehabilitation of veterans with TBI. Evaluating the outcomes of these rehabilitation activities requires measuring whether they improve veterans' lives in a meaningful way, with specific focus on improving the ability of veterans with TBI to join in normal work and community activities. This type of social activity is referred to as "participation"; participation in work and community activities is strongly linked to perceived quality of life. This article considers issues related to improving the measurement of social participation in veterans with TBI to help improve the meaningful evaluation of rehabilitation efforts.

TBI is an injury that disrupts the normal function of the brain. TBI severity may range from mild (a brief change in mental status or consciousness) to severe (an extended period of unconsciousness or amnesia after the injury) [1]. TBI is often classified as either closed or penetrating and may result from a number of different types of events, including sudden acceleration or deceleration of the head (e.g., motor vehicle accident or fall), penetrating injury (e.g., gunshot wound), or blast injury (e.g., explosion). TBI of all types can result in the immediate rupture of cellular and vascular membranes with impaired cerebral blood flow followed by necrotic and apoptotic cell death and with subsequent hypoxia, hypotension, and increased intracranial pressure [2]. Newer imaging techniques have indicated that cytoskeletal damage may contribute to diffuse axonal injuries that disrupt nerve cell and network functioning [2]. However, understanding that all types of TBI can and often do co-occur with multiple other injuries, including significant cardiopulmonary, burn, or musculoskeletal injuries and posttraumatic stress disorder (PTSD), is important [2-3]. This is especially true with TBI in a combat environment. Mild TBI and PTSD present diagnostic challenges because symptoms may overlap, and the entire constellation of injuries complicate and compound each other.

Population-based epidemiological studies in the U.S. civilian population provide insights into the magnitude of TBI in the United States. The annual incidence of U.S. civilians with TBI is estimated to range from 0.4 to 0.8 percent [1-2], or 1.2 million to 2.4 million persons experiencing TBI each year. A 2010 Centers for Disease Control and Prevention report identified 1.7 million U.S. civilians incurring a TBI each year, with 80 percent of these being treated and released from hospital emergency departments, 16 percent hospitalized, and 3 percent fatalities [4].

Although no population-based epidemiological studies stratify incidence and prevalence data by TBI severity in veteran and military populations, some data provide insight into the occurrence of TBI for these groups. Estimates of the number of veterans and military servicemembers with TBI vary widely according to the data sources and research methods employed in a given analysis. According to the Department of Defense, about 35,000 servicemembers have been wounded in action as of 2009 [5], or about 2 percent of the 1.6 million servicemembers who have served or are serving in Operation Iraqi Freedom and Operation Enduring Freedom over the past decade. However, some researchers have suggested that perhaps around 70,000 of these 1.6 million servicemembers (4\%) have sustained a TBI [6], while others have suggested much higher numbers, perhaps as many as $320,000(20 \%)$ [7-9]. These estimates of the magnitude of possible TBI in military personnel range from approximately 2 to 10 times greater than the total number of servicemembers identified as wounded in action, and therefore include individuals who were not officially identified as wounded during their tour of duty. Injuries not initially recognized during tour of duty would almost exclusively be expected to be mild injuries.

While the data regarding the magnitude of mild TBI in military servicemembers and veterans are very concerning, it is also important to recognize that mild TBI and what is sometimes called "postconcussive disorder" have poor diagnostic reliability and validity. Many postconcussive symptoms such as headache, sleep disturbance, and difficulty concentrating have a base rate in the general nondisabled population ranging from 6 to 80 percent depending on the specific symptom [10-13] and are also found in individuals with anxiety [14], depression 
[15], PTSD [16], and pain [17-18]. In addition, TBI is commonly diagnosed using neuropsychological assessments, but interpretation of such assessment results can be confounded by the 5 to 85 percent incidence of false positive neuropsychological findings in nondisabled populations (depending on the number of tests and the cutoff level for identifying positive findings [19]).

Using the most common definitions of severity, a 2009 Institute of Medicine study considered over 30,000 published studies and found an association between moderate to severe TBI and neurocognitive deficits, as well as problems with long-term employment and social relationships. However, no clear association was found between mild TBI and objectively measured neurocognitive deficits or long-term employment, social relationships, and ability to live independently [2].

Although it is important to consider the multiple factors and complex issues related to accurately identifying and diagnosing TBI, it is also important to provide assistance to military servicemembers and veterans who experience functional difficulties. It is important that the VA provide resources to improve veterans' ability to function, regardless of the relative contribution of TBI, anxiety, depression, PTSD, sleep disorder, pain, substance abuse, or other factors confounding diagnosis. Targeted interventions to improve specific areas of difficulty, especially difficulties in community and vocational participation, may be more important than diagnostic categorization.

It is important that interventions designed to improve veterans' social and vocational participation be studied using valid, reliable, and sensitive measures. One set of particularly relevant measures that can help inform the rehabilitation process involve measuring how successful individuals are in participating in usual social role activities, i.e., working; engaging in leisure and recreational activities with others; and being part of family, neighborhood, and community interactions. Precise and comprehensive measurement of rehabilitation outcomes related to participation is needed to meaningfully evaluate and compare the results of different rehabilitation interventions designed to improve the lives of veterans with known or suspected TBI.

Therefore, this article considers the issues involved in measuring rehabilitation outcomes regarding social participation in veterans with possible, probable, and confirmed TBI. Specifically, we will-

- Discuss conceptual models of participation.
- Review participation subdomains and their instruments of measurement.

- Identify current research issues and needs related to measurement of participation.

- Make suggestions for the future development of participation measures.

\section{CONCEPTUALIZING PARTICIPATION}

Medical advances have led to more veterans and military personnel surviving acute injury and illness and then living with chronic health conditions. This creates a need for conceptual models to understand disablement. In the conceptual model of the World Health Organization International Classification of Functioning, Disability, and Health (ICF) [20], rehabilitation outcomes can be considered in a three categories. "Body Functions and Structures" refers to the physical level of body structures and their associated functions. "Activities" occurs at the task level and involves such things as feeding, dressing, shopping, and operating a motor vehicle. "Participation" occurs at the societal level and is an interaction between the person and the environment in social roles, involving such things as being a worker, student, friend, spouse, parent, or citizen. While rehabilitation interventions to improve body functions and structures and activities are certainly important, it is participation that is most strongly linked to perceived quality of life. However, participation in social role activities is challenging to conceptualize and measure.

\section{DEFINING PARTICIPATION}

The ICF was the first model of disability to use the term participation to refer to "involvement in life situations," but the concept of participation as involvement at the societal level has appeared in all prior models of disability. For example, earlier models used different terms than participation, including "handicap" to indicate a disadvantage in society [21] and "disability" to indicate problems with social role fulfillment [22-24]. Although participation is a useful term to describe involvement in family, community, and work roles, the ICF does not operationally define participation in a way that distinguishes it from other concepts such as activity and quality of life. 
It is important to conceptually distinguish participation from activity. As Whiteneck and Dijkers state, "activities are the physical and cognitive tasks performed by individuals, while participation is social role performance as a member of society" [25; p. 24]. The ICF has been criticized for not adequately differentiating participation from activity (at the person level) either definitionally or in its single taxonomy of activity and participation category codes [26-27].

Measures of participation are also difficult to distinguish from measures of global life satisfaction such as quality of life [26]. In contrast to the multidimensional health-related quality of life construct [27], unidimensional quality of life measures evaluate general wellbeing [28-29]. It is unclear whether subjective measures of one's satisfaction with participation differ from subjective judgments of well-being, which have been conceptualized as encompassing eudemonic concepts such as purpose in life, personal growth, positive relations with others, environmental mastery, self-acceptance, and autonomy, as well as hedonic concepts such as happiness and life satisfaction [30].

The ICF also does not clearly conceptualize how the interaction between the person, the task, and the environment affects participation. It is important to recognize that disability is a person-task-environment interaction arising from the individual's condition, the task in which they are engaged, and the environment in which they engage with the task. For example, wheelchair users are less disabled in communication tasks than in mobility tasks, less disabled in physical environments with paved sidewalks and ramps than in physical environments without such structures, and less disabled in social environments with acceptance of variations in body functions and structures than in social environments without such acceptance. Therefore, participation is affected by aspects of an individual's physical condition; motor and cognitive functioning; availability and use of assistive devices; and the physical, social, and public-resource environments in which they live.

In addition, we may need to expand definitions of participation to include some unexplored areas that could be important from a conceptual standpoint. Attention has not been given to the concept of negative participation, wherein individuals engage in antisocial or illegal interpersonal activities. Cyberparticipation, wherein individuals interact without direct or even real-time contact with others, is beginning to be incorporated into concepts of participation. Hyperparticipation, wherein individuals engage in greater amounts of interpersonal activities than they desire (when family, school, community, and work demands exceed their preferences), has also not been discussed in models of participation.

In summary, a clear and commonly accepted definition of participation, distinct from activity and quality of life, is needed to develop operational definitions and measurement instruments [25]. The field of rehabilitation outcome assessment could also be enhanced by more explicit incorporation of person-task-environment interactions into these assessments. Inclusion of conceptual variations on participation, such as negative participation or overparticipation, may also be helpful.

\section{MEASURING PARTICIPATION}

In addition to conceptual clarification, improving the practical enumeration of types of participation (distinct from activity and quality of life) is also needed to advance the field of rehabilitation outcome assessment [25]. As with the overall definition of participation, agreement on the key subdomains of participation and their measurement would be helpful. Whiteneck and Dijkers discuss that participation can be measured using objective indices such as marital and employment status, counts of social activities engaged in, and inventories of common social activities [25]. These objective approaches have been criticized as neglecting important individual variation, especially with respect to how people with disabilities may prefer to participate and how as a group, they may differ in important ways from the nondisabled population upon which such measures are typically based. It is not clear that participation is best measured by counting the number of social engagements. Participation may include issues related to amount, but people pick and choose their participation according to preferences and perceived importance and difficulty, and thus the subdomains are not hierarchical in nature (one type of activity does not necessarily precede or follow another) [25]. Optimal participation, rather than maximal participation, may be most important, involving the perceived characteristics of those interactions (preference, importance, and difficulty) [25].

Measuring participation that is specific to individuals with TBI is also complex. First, individuals may have mild, moderate, or severe injuries, and their specific injuries may 
result in different types of disabilities. Second, we must consider the stage and trajectory of recovery during which assessments are made. Third, although this population is heterogeneous, some types of impairment frequently occur that may directly affect a person's ability to reliably and accurately communicate their thoughts and behaviors. These include deficits in motor function, thinking and memory, communication and social pragmatics, affective self-regulation, and accurate awareness of self and others, which may compromise the validity of self-report measures with this population [31-32]. Fourth, some participation measures are completed by knowledgeable caregivers, and the degree to which these reports may or may not agree with the person's own report varies according to the type and degree of injury and the type of participation measured [33-34]. Despite these difficulties, valid, reliable, and sensitive outcome measures are needed that can help inform the rehabilitation process by examining how successful individuals with TBI are in returning to their families, communities, and work and social involvements. This article discusses existing and developing instruments for measuring participation in persons with TBI in relation to these issues.

\section{ESTABLISHED ASSESSMENT TOOLS}

Although a number of different assessment tools have been developed to assess participation in individuals with a variety of disabilities, the majority of these are generic and not specific to persons with TBI. Fortunately, recent measurement developments specifically target the assessment of TBI-related participation issues. This article does not attempt to provide a systematic or exhaustive review of all assessment tools for measuring participation; rather, it discusses assessment tools that have been specifically developed to evaluate participation for persons with TBI.

One of the first assessment tools developed to examine participation was the Community Integration Questionnaire (CIQ), which includes an objective measure of participation in TBI samples (type and frequency of activities). The complementary development of the Participation Objective-Participation Subjective Scale (POPS) and the Mayo-Portland Adaptability Inventory (MPAI) provides subjective assessment of participation in TBI (amount of assistance needed). This development work was further extended by the Participation Assessed with Recombined Tools (PART), which takes items from each of these measures (CIQ, POPS, MPAI) as well as the Craig Handicap Assessment and Reporting Technique (CHART), to develop a more sensitive tool appropriate for use in TBI.

\section{Community Integration Questionnaire}

The CIQ is a 15-item questionnaire developed to assess three domains of community participation: home integration (4 items involving household chores and child care), social integration (8 items involving leisure and social networks), and productivity (3 items involving work and school or volunteer participation) [35]. The items in the home integration and social integration subscales are rated for levels of independence in participation, the frequency of participation, and if social interaction is involved, with whom the individual participates in the activity. For the productivity subscale, the level of participation is rated on the hourly amount of participation (full- vs part-time participation in school or work) and the frequency of participation. The questionnaire yields a total score and three subscale scores, with higher scores representing higher levels of community integration. The CIQ can be conducted in person and over the telephone and is designed for use with the individual and/or a significant other.

The CIQ is the most widely used community outcome measure in TBI rehabilitation [36]. Its strengths include brevity [36-37], orthogonal subscales [36], and high testretest reliability [35]. The CIQ was able to discriminate individuals with TBI from nondisabled individuals and also showed differentiation of scores in a TBI sample grouped according to living situation (e.g., independent living, living with supports, institutional setting) [35].

However, a number of critiques of the CIQ exist. First, the development of the instrument was based on principal components analysis of data from a sample of 49 individuals with TBI, which may have been too small to provide adequate statistical power. Second, although subsequent replication of the analysis verified the factor structure, this replication did not include each of the original 47 items and indicated lack of fit for two items (shopping and child care) $[36,38]$. Third, interrater reliability was initially assessed to be acceptable [35], but later studies using the more accurate intraclass correlation coefficient produced less robust results, especially for the social integration and productivity scales [38-39]. Fourth, the CIQ does not correlate highly with other measures of participation and/or 
disability and thus may represent measurement of a unique domain of participation or may not assess some relevant constructs [40-41]. Fifth, an individual's score can be adversely affected by their level of premorbid participation (e.g., if they never did household chores), need for less supervision, and/or availability of the activity or need for participation in the activity (e.g., child care) $[36,38,42]$. Sixth, demographic factors and cultural values can influence the findings, but no controls are included for these effects in scoring or normative development [4347]. Seventh, although the sensitivity of this assessment tool's ability to distinguish individuals with and without disability is well established, it is less able to detect change as the result of an intervention [40]. Finally, the priorities of the individual are not included in the CIQ, and critiques have been directed at the lack of consideration of the relevance of specific areas of participation to certain TBI stakeholders (e.g., patients, families, healthcare professionals, employers) [48].

\section{Participation Objective-Participation Subjective Scale}

The POPS was developed to prioritize the preferences and goals of the individual with TBI and to map more closely to the ICF [26]. The POPS is a 26-item selfreport assessment tool evolved from a research measure with data gathered from 454 individuals with TBI in the community and 126 nondisabled individuals. It includes both an objective (participation objective: frequency or duration of engagement) and a subjective measure (participation subjective: importance of activity and satisfaction with level of engagement) of participation. Areas of participation are organized into five subscales that were conceptually derived and conform to ICF categorization: domestic life; interpersonal interactions and relationships; major life areas; transportation; and community, recreational, and civic life. The participation objective portion of the questionnaire quantifies participation as proportion of responsibility, number of hours, or frequency of participation, depending on the area of life measured. The participation subjective portion quantifies the importance of the activity to the individual and the desire for change in the level of participation. The two subscales are summed into weighted averages, either using the mean ratings of the standardization sample (participation objective) or using the importance rating of the individual (participation subjective).
The test-retest reliability coefficients for the total scores were adequate (intraclass correlation coefficient of 0.75 and 0.80 , respectively, for the participation objective and participation subjective total scores); however, the range for the subscale scores was more variable, with weaker reliability for the transportation and community, recreational, and civic life subscales (0.28 and 0.37, respectively) [26]. The subscales appear to be orthogonal on the participation objective dimensions, indicating that the types of activity are different, but share correlations on the participation subjective dimension, indicating a coherent measurement of value.

The authors compared the scores of individuals with TBI with those without disability and found that the ratings of the importance of various activities did not significantly differ between the groups [26]. The authors compared the scores of individuals with mild TBI with those with moderate to severe TBI and found that level of participation did not significantly differ, but that satisfaction with participation was lower for the individuals with mild TBI [26].

To date, the literature has reported no validation of the POPS using other instruments of participation, and this remains a major limitation. In addition, although the authors note that environmental factors could affect the ratings of participation and/or satisfaction, this potential confound is not included in the measure as a factor that affects level of participation. In sum, while the POPS holds some promise, further evaluation is needed to determine whether it is valid and reliable in outcome assessment of participation in rehabilitation trials.

\section{Participation Assessed with Recombined Tools}

The PART represents an attempt to select the best items from existing instruments of participation [49-50]: the second edition of the CIQ [51], the POPS [26], and the CHART [52]. Items from these instruments were merged into a single instrument and administered to a sample of 400 individuals with TBI at 8 of the 16 Federal TBI Model Systems programs as they crossed their 1st, 2nd, 5th, 10th, and 15th year anniversaries of injury. Using a combination of factor analysis, Rasch analysis, and content analysis, the authors identified 24 items that formed a new scale (PART) of participation (being productive, socially integrated, and engaged in community life) demonstrating good psychometric properties [49]. The authors selected all 24 PART items to measure participation objectively (hours spent in productive activities, 
frequency of involvement in social and community aspects of participation, etc.), but they also identified the need for subjective measures of participation, and a subjective tool is currently under development. The PART is limited by the limitations of the measures it incorporates because it did not include the validation of new items.

The PART correlates strongly with other measures of participation and with measures of impairment, physical and cognitive functional performance, and satisfaction. Specifically, the PART demonstrates significant correlations with the MPAI 8-Item Participation Index (M2PI), the Cognitive Functional Independence Measure, the Motor Functional Independence Measure, the Supervision Rating Scale, the Glasgow Outcome ScaleExtended, and the Dementia Rating Scale, indicating that greater functional independence is associated with greater participation [49]. In addition, the PART is significantly associated with the Satisfaction with Life Scale [49]. Because of these strengths, it was adopted as the measure of participation currently included in the TBI Model Systems National Database [50].

\section{Mayo-Portland Adaptability Inventory 8-Item Participation Index}

The M2PI is an 8-item participation index taken from the 30-item MPAI [53]. Currently in its fourth edition, the MPAI was designed and validated to assess the overall level of disability across three different domains: abilities, adjustment, and participation (the latter comprising the 8 items of the M2PI). The M2PI covers eight domains of social participation: initiation, social contact, leisure, self-care, residence, transportation, employment, and money management. All items use a 5-point rating scale ranging from 0 (no problem) to 4 (severe problem) and were designed to reflect the World Health Organization's distinction between impairment, activity, and participation [54]. The M2PI was developed and validated in persons with TBI [55] and demonstrated strong internal consistency, especially when self-ratings for people with TBI were compared with proxy ratings (support staff and significant others) [55-56]. It appears to have only minimal floor and ceiling effects [57].

Because of the limited psychometric data supporting the M2PI, it is important to provide a brief review of the psychometric properties of the measure from which it was derived, the MPAI. The MPAI shows good to excellent internal consistency (Cronbach $\alpha=0.89$, Rasch Person Reliability $=0.88$, Rasch Item Reliability $=0.99$ )
[58]. Evidence for its concurrent validity is supported by correlations with the Disability Rating Scale [59] and the Rancho Los Amigos Cognitive Scale [60]. In addition, the MPAI is a good predictor of vocational placement and outcome [61-62] and community-based employment [63] in individuals with TBI. The MPAI is also a good predictor of level of functioning, return to employment, and independent living in TBI [64]. Given the importance of community integration and vocational outcomes to individuals and their families, and the significant Federal efforts to improve vocational outcomes in veterans and persons with disability, the correlation of the MPAI and M2PI with community employment may make these especially important tools in rehabilitation outcome measurement.

\section{EMERGING MEASURES OF PARTICIPATION}

Although it is important to consider the conceptual differences between participation and quality of life, participation is correlated with quality of life, and therefore, quality of life measures can be helpful in studying participation. As previously discussed, TBI researchers have tended to use generic quality of life measures, developed for use in the general population, which can lack the sensitivity needed to detect meaningful differences in individuals with TBI and often contain irrelevant material and omit issues that are important to individuals with TBI.

For these reasons, the National Institute on Disability and Rehabilitation Research (NIDRR) has prioritized research that "leads to the development of the next generation of valid and reliable measures of health and functional status among people with disabilities" [65] Such projects also have the support of the National Institutes of Health (NIH), National Institute of Neurological Disorders and Stroke, National Center for Medical Rehabilitation Research, and the VA Rehabilitation Research and Development (RR\&D) Service. The development of valid and meaningful instruments that measure health-related quality of life specific to individuals with TBI is an important step in TBI outcomes research. Most recently, two measurement initiatives are creating item banks examining social participation using state-of-the-art measurement development approaches. Specifically, the TBI-Quality of Life (TBI-QOL) and the PolytraumaQuality of Life (Polytrauma-QOL) are using item 
response theory methodology to develop computer-adaptive tests of participation in individuals with TBI.

\section{Traumatic Brain Injury-Quality of Life}

The TBI-QOL is currently being developed as a meaningful, relevant, and psychometrically sound measure that provides comprehensive assessment of healthrelated quality of life for persons with TBI [66]. Further, the TBI-QOL will allow for comparison of the healthrelated quality of life of individuals with TBI with the health-related quality of life of persons with other neurological conditions.

The TBI-QOL uses methodology employed by other NIH-funded, larger-scale initiatives (e.g., http:// www.promis.org/ and http://www.neuroQOL.org/). Specifically, focus groups were conducted with a diverse sample of individuals with TBI, their caregivers, and interdisciplinary teams of healthcare providers to discuss issues related to quality of life. Major content areas were identified and coded, including emotional health, cognitive functioning, physical/medical health, sexual functioning, personality changes, and (of interest to this article) social functioning. Item banks are under development for social functioning that will include both social role performance and social role satisfaction items related to leisure functioning, interpersonal relationships, vocational functioning, and independence/autonomy.

The TBI-QOL will provide a specialized outcome measure that assesses the needs of individuals with TBI. It will evaluate areas of functioning that are unique to TBI, plus include a number of items that will allow for crossdisease comparison with other neurologically based diseases.

\section{Deployment-Related Traumatic Brain Injury/ Polytrauma-Quality of Life}

The VA RR\&D Service grant program has funded a study to adapt the TBI-QOL for use in the VA system with individuals with TBI. The VA study uses a similar design as the TBI-QOL: new item banks will be developed using veteran focus groups, item response theory analyses will be performed to develop short forms, and ultimately, the Polytrauma-QOL will be administered as a computeradaptive testing (CAT) methodology. The long-term goal of the Polytrauma-QOL is to develop a clinically sensitive scale for clinical trials, program evaluation, and outcome monitoring in clinical practice with individuals with deployment-related TBI. Ultimately, the final product of this project-a conceptually grounded, deploymentrelated TBI health-related quality of life assessment tool-will be integrated with larger NIH- and NIDRRsponsored rehabilitation outcomes assessment projects to allow results obtained in samples of military servicemembers with TBI to be directly compared with samples of nonmilitary individuals with TBI and also to veterans and nonveterans with other neurologic disorders.

\section{Newer Areas of Participation}

While some current measures of participation, such as the Community Participation Indicators measure, include items such as communicating on the telephone and by email as examples of social activity, future participation measures will undoubtedly also include participation in electronic social networking (e.g., Facebook and Twitter). Studies in nondisabled populations suggest that using Facebook can enhance "social capital," particularly for those with lower self-esteem [67]. Although some studies suggest that the effect is small in nondisabled college students [68], electronic social networking may assume a more prominent role in the lives of people who are housebound or whose "traditional" participation is restricted. Thus, electronic social networking is likely to gain a place in the armamentarium of participation measurement in medical rehabilitation populations, including TBI.

\section{RESEARCH METHODS AND GAPS}

Similar to other areas of rehabilitation outcome measurement, developing measures of participation for individuals with TBI faces multiple challenges. In this section, we discuss limitations of existing measurement development efforts and methods by which improved measures of participation can be developed and tested. In particular, we will discuss using qualitative methods and item response theory to guide measurement development. We then turn to measurement issues specific to the TBI population that present challenges for measurement development and opportunities for research.

\section{General Considerations in Measurement Development}

The process of developing assessment tools measuring any domain or construct involves developing items and rating scales and then evaluating the function of these items and scales relative to a given study population. Creation of test items should meet the criterion of 
contemporary qualitative and quantitative methodologies. Guidelines from the U.S. Food and Drug Administration (FDA) for the development of Patient Reported Outcome for pharmaceutical labeling [69] may be a useful framework for developing test items to measure aspects of participation. Of particular relevance is the FDA requirement of incorporating interviews or focus groups from a wide range of patients, across a variety of severities and population characteristics (e.g., age, sex), into item generation process. Because of the broad scope of participation, qualitative approaches such as focus groups may be particularly useful in determining themes and content areas and could potentially be used to generate item pools for new measurement instruments.

State-of-the-science item-pool development strategies include techniques such as binning and winnowing [70]. Binning involves the systematic grouping of items according to specific subdomains. Winnowing involves reducing item pools to a representative set of items. This process involves consensus among item developers as to whether particular items should be included or excluded based on operational definitions of subdomains. Cognitive interviewing and debriefing strategies are also becoming standard procedures for test item development [71]. This approach involves presenting items to potential respondents to obtain detailed information regarding item interpretation. This may be particularly effective in ensuring that test items are readable and understandable by individuals from different ethnic and socioeconomic backgrounds.

Older measures of participation have used classical test theory as the dominant framework for both instrument development and psychometric evaluation. While classical test theory methodologies examine the properties of the test as a whole, it is also necessary to look at the function of the items and the scale used to rate item responses. Item response theory examines the function of items relative to a person's ability [72-73]. Classical test theory methods, such as factor analysis, hierarchical linear modeling, structural equation modeling, and cluster analysis, in combination with item response theory methods, such as fit statistics, item difficulty calibrations, item discrimination, tests of monotonicity (rating scale analysis), and differential item functioning, are all important for test development.

The development and testing of the Activity and Participation Measures for Post Acute Care and the development of the TBI-QOL are good examples of this development method. The measures have been examined with classical test theory and item response theory methods to address questions related to uni- versus multidimensionality. First, correlations are computed between the individual items and the total scores (i.e., sum of the individual items within a subdomain), as well as the total scores of other criterion measures, are used to determine which items are retained and which items are eliminated. Item response theory methods are then employed to calibrate the remaining test items in preparation for building a CAT version. CAT allows evaluators to administer item subsets that ease administrator and respondent burden, while maintaining good psychometric properties.

Existing evidence largely supports the idea that scales measuring major life domains, such as participation, can be constructed along a dimension of more to less (e.g., more to less participation limitation or participation satisfaction). Ultimately, however, a more complex model may be needed to fully reflect the complexity of life participation [74]. This is illustrated by recent efforts to develop measures of social health [75]. The Patient-Reported Outcomes Measurement Information System social domain workgroup used focus groups and expert opinion (i.e., Delphi methods) to develop the content of a social domain framework. The framework consisted of two primary branches: social function and social relationships. Participation ability and satisfaction, rather than participation frequency, were the two subdomains selected under social function. Positively and negatively worded test items to measure these two subdomains were obtained from existing instruments and new items were developed to fill gaps. Limitations in reaching a unidimensional structure and inconsistencies in item-difficulty hierarchical ordering (such as more or less) suggest that a unidimensional item response theory model may not be applicable to measuring participation [25].

\section{Traumatic Brain Injury-Specific Considerations}

While the psychometric methods described are relevant to the development of any type of measure, the development of participation measures specific to TBI poses unique challenges. The reliance on self-report causes characteristic challenges for research on TBI because the reliability of self-report may be affected by TBI-specific cognitive impairments such as difficulties in communication, memory, and awareness of limitations [31-32]. The reliability of proxy report following TBI also seems to vary systematically by the area of participation, with 
activities related to economic productivity showing more robust self-proxy report agreement compared with home and social activities [33-34].

It is important to note that even instruments that use multiple and complementary measurement methods and input from multiple stakeholders are susceptible to biases. For example, in a recent study [33] of self- versus proxy-report at 1 year post moderate to severe TBI using the Community Participation Indicators measure [34], items pertaining to economic and community activities showed high concordance. However, specific activities that might be important for health studies showed surprisingly low agreement (e.g., frequency of exercise outside the home). Social activities, even those that might be objective or observable (e.g., frequency of getting together with family and friends), also showed surprisingly low agreement. Satisfaction with the degree of participation showed low self-proxy reliability, although proxies who spent time with participants every day had significantly better congruence.

It is theoretically possible to bypass these problems with self- and proxy-report by directly measuring the objective aspects of participation through behavioral observations or by technologies such as personal digital assistants (PDAs). Seekins et al. demonstrated the measurement of direct behavioral observations using Ecological Momentary Assessment. Ecological Momentary Assessment is a behavioral recording technique that allows the participant to record specific data in response to external triggers, such as an alarm, or internal events, such as feeling irritated [76]. In a pilot study, people with disabilities involved in vocational development were given PDAs and asked to record data across a 9-month period. Data collected for 7 weeks, spaced across the study interval, included what the participant was doing; where and with whom; whether there were barriers or facilitators present; and how the participant felt, including level of fulfillment reached by engaging in the activity. Results suggested that high levels of connectedness and fulfillment occurred during employment, seeking employment, and other community-based pursuits, with lower levels for home activities (either home management or leisure activities). The context of an activity (especially participation with others outside the home) was more strongly related to fulfillment than the actual content of the activity.

In summary, researchers face a number of challenges in developing new instruments and refining existing instruments to measure participation outcomes in TBI. While these challenges relate to measuring participation in general, additional complexities exist that are unique and specific to TBI. Given that TBI rehabilitation aims to enhance participation, the measurement of participation after TBI is important, and emerging methods may be useful in producing effective measures of participation. Suggestions to advance the field of measuring participation in persons with TBI are discussed later.

\section{MOVING THE FIELD FORWARD}

Based on this review of currently available and emerging instruments and issues related to the measurement of participation, we identified two avenues for advancing the field of participation measurement in persons with TBI. The focus of this article is on veterans with TBI; however, this does not limit the applicability of these recommendations to the VA alone, and where possible, extension of these recommendations to non-VA settings is discussed. First, we describe suggestions to facilitate the immediate implementation of participation measurement in TBI clinical practice and TBI rehabilitation research. Second, we describe recommendations for future research initiatives specific to participation in persons with TBI.

\section{Immediate Implementation Strategies}

The VA has been a leader in implementing evidencebased healthcare. In accordance with these efforts, we describe suggestions to encourage adoption and use of participation measures in VA TBI clinical programs and research initiatives. These suggestions capitalize on the expertise and resources that already exist in the VA and encourage dialog between the various clinical programs and research services to enhance state-of-the-science implementation

\section{Basic Research: Develop Evidence-based Synthesis Program Priority}

We suggest that the VA, in conjunction with other Federal agencies and academic and clinical centers of excellence, conduct evidence-based reviews of the psychometric properties (i.e., reliability, validity, precision) of existing instruments for measuring participation specific to persons with TBI. The evidence-based review summary suggested here should clearly delineate the psychometric properties 
and areas of measurement for each instrument and the evidence for using the instruments with TBI. The review should provide evidence-based criteria that can be used by readers to guide the selection of existing participation measures for use in TBI patient outcome measurement. This review would provide a basis for identifying which existing measures should be refined and which areas of participation measurement need further development. The VA's existing Evidence-based Synthesis Program, funded by the Health Services Research and Development Service (http:// www.hsrd.research.va.gov/publications/esp/), could conduct this evidence-based review in cooperation with other public and private partners. Coordinating existing expertise in rehabilitation will ensure that the systematic review of the literature is (1) relevant to quality healthcare services for veterans, (2) evidence based, and (3) compatible with ongoing investigations of TBI diagnosis and treatment already funded by the VA and other Federal agencies.

\section{Clinical Integration: Develop a Rehabilitation Medicine Assistant}

Instruments that measure participation are important in assessing TBI rehabilitation outcomes. Coordination of VA clinical practice groups involved in TBI care with the VA Polytrauma Network teams is critical for standardizing participation measurement in clinical rehabilitation treatment protocols and to the use of participation measures in tracking clinical rehabilitation outcomes. We suggest that a VA Rehabilitation Medicine Assistant be developed, similar to the Mental Health Assistant, as part of the Clinical Patient Record System. The Rehabilitation Medicine Assistant would be based on an evidence-based review and periodically modified using feedback from subject-matter experts in TBI rehabilitation and participation measurement. It would make participation measurement instruments readily available to clinicians and researchers, which would facilitate the integration of these into clinical care planning and treatment goal setting. This would provide important information about the real-world rehabilitation outcomes that are most important to patients and families.

\section{Ensure that Measurement of Participation Enhances Rehabilitation Quality}

In order to examine the extent to which participation measurement provides useful feedback to rehabilitation teams and improves treatment outcomes for persons with TBI, we recommend that a VA Quality Enhancement
Research Initiative priority be established to examine the performance of participation measures identified in this article (http://www.queri.research.va.gov/). These participation measures could be examined in different clinical settings to identify their utility in individual patient treatment planning and the relationship of participation measures to healthcare outcomes. This research is vital to the development of future clinical translation trials helping to reintegrate veterans into their homes, communities, and social roles.

\section{Future Research Priorities}

Public policy and legislative efforts recognize the importance of work and social participation for veterans with TBI. These efforts include creating stable housing programs to ensure safe and adequate accommodations for veterans with disabilities, providing healthcare services to optimize rehabilitation outcomes and social participation, and creating job opportunities and incentives for employers to hire veterans. However, reliable, valid, and relevant measures of the effectiveness of these programs should be improved. Such research can be used to improve care, inform public policy, and guide legislative efforts.

In this article, we identified gaps that could be successfully addressed through organized research efforts. The primary areas for future research are (1) developing a solid theoretical base upon which to build measurement efforts in this area, (2) refining existing measurement instruments to incorporate issues specific to TBI rehabilitation with veterans, and (3) developing individual participation profiles to understand personal preferences and guide clinical rehabilitation goal setting and treatment planning that is relevant to specific individuals. Within these efforts, it is important to consider what constitutes meaningful change for the individual and what effect participation has on individuals' well-being and quality of life. Emphasis on measurement of rehabilitation outcomes that are based in the real-world experience of the individual and that complement other TBI rehabilitation outcomes will be valuable for our nation's veterans and would be potentially generalizable to civilians and other disability populations. Developing these methodologies and measures will contribute substantially to the improvement of intervention efforts to aid our nation's veterans and are critical to advancing the science of measuring participation for persons with TBI. 


\section{ACKNOWLEDGMENTS}

\section{Author Contributions:}

Drafting of manuscript: W. Stiers, N. Carlozzi, A. Cernich, C. Velozo, T. Pape, T. Hart, S. Gulliver, M. Rogers, E. Villarreal, S. Gordon, W. Gordon, G. Whiteneck.

Critical revision of manuscript for important intellectual content: W. Stiers, N. Carlozzi, A. Cernich, C. Velozo, T. Pape, T. Hart, S. Gulliver, M. Rogers, E. Villarreal, S. Gordon, G. Whiteneck.

Financial Disclosures: The authors have declared that no competing interests exist.

Funding/Support: This material was based on work supported by the State of the Art Conference on Outcome Measures in Rehabilitation, VA Office of Research and Development.

Additional Contributions: Dr. Carlozzi is now with the Department of Physical Medicine and Rehabilitation, University of Michigan Health System, Ann Arbor, Michigan.

\section{REFERENCES}

1. National Center for Injury Prevention and Control. Traumatic brain injury [Internet]. Atlanta (GA): Centers for Disease Control and Prevention; 2011 [updated 2011 Oct 6; cited 2010 Mar 11]. Available from: http://www.cdc.gov/ ncipc/tbi/TBI.htm

2. Institute of Medicine. Gulf war and health. Volume 7: Long-term consequences of traumatic brain injury. Washington (DC): The National Academies Press; 2009.

3. Vasterling JJ, Verfaellie M, Sullivan KD. Mild traumatic brain injury and posttraumatic stress disorder in returning veterans: Perspectives from cognitive neuroscience. Clin Psychol Rev. 2009;29(8):674-84. [PMID: 19744760] http://dx.doi.org/10.1016/j.cpr.2009.08.004

4. Faul M, Xu L, Wald MM, Coronado VG. Traumatic brain injury in the United States: Emergency department visits, hospitalizations and deaths 2002-2006 [Internet]. Atlanta (GA): Centers for Disease Control and Prevention; 2010 [updated 2010 Sep 23; cited 2010 May 31]. Available from: http://www.cdc.gov/traumaticbraininjury/tbi ed.html

5. DoD worldwide numbers for traumatic brain injury [Internet]. Washington (DC): Department of Defense; 2009 [updated 2011 May 16; cited 2010 Mar 11]. Available from: http://health.mil/Research/TBI_Numbers.aspx

6. Jaffee M, French L, Cifu D. TBI in the military and veterans: From field to community. Proceedings of the 8th World Congress on Brain Injury; 2010 Mar 10-14; Washington, DC.

7. Golding H, Bass E, Percy A, Goldberg M. Understanding recent estimates of PTSD and TBI from Operations Iraqi Freedom and Enduring Freedom. J Rehabil Res Dev. 2009; 46(5):vii-xiv. [PMID: 19882489] http://dx.doi.org/10.1682/JRRD.2009.06.0081
8. Tanielian TL, Jaycox L. Invisible wounds of war: Psychological and cognitive injuries, their consequences, and services to assist recovery. Santa Monica (CA): RAND; 2008.

9. DoD worldwide numbers for traumatic brain injury [Internet]. Washington (DC): Defense and Veterans Brain Injury Center; 2009 [updated 2011 May 16; cited 2010 Mar 17]. Available from: http://www.dvbic.org/TBI-Numbers.aspx

10. Gouvier WD, Uddo-Crane M, Brown LM. Base rates of postconcussional symptoms. Arch Clin Neuropsychol. 1988; 3(3):273-78. [PMID: 14589697]

11. Iverson G, Lange R. Examination of "postconcussion-like” symptoms in a healthy sample. Appl Neuropsychol. 2003; 10(3):137-44. [PMID: 12890639$]$ http://dx.doi.org/10.1207/S15324826AN1003 02

12. Machulda MM, Bergquist TF, Ito V, Chew, S. Relationship between stress, coping, and postconcussion symptoms in a healthy adult population. Arch Clin Neuropsychol. 1998; 13(5):415-24. [PMID: 14590606]

13. Sawchyn JM, Brulot MM, Strauss E. Note on the use of the Postconcussion Syndrome Checklist. Arch Clin Neuropsychol. 2000;15(1):1-8. [PMID: 14590562]

14. Suhr JA, Gunstad J. Postconcussive symptom report: The relative influence of head injury and depression. J Clin Exp Neuropsychol. 2002;24(8):981-93. [PMID: 12650225] http://dx.doi.org/10.1076/jcen.24.8.981.8372

15. Iverson GL. Misdiagnosis of the persistent postconcussion syndrome in patients with depression. Arch Clin Neuropsychol. 2006;21(4):303-10. [PMID: 16797916] http://dx.doi.org/10.1016/j.acn.2005.12.008

16. Fox DD, Lees-Haley PR, Earnest K, Dolezal-Wood S. Postconcussive symptoms: Base rates and etiology in psychiatric patients. Clin Neuropsychologist. 1995;9(1):89-92. http://dx.doi.org/10.1080/13854049508402064

17. Iverson G, McCracken L. "Postconcussive" symptoms in persons with chronic pain. Brain Inj. 1997;11(11):783-90. [PMID: 9354255] http://dx.doi.org/10.1080/026990597122990

18. Gasquoine P. Postconcussional symptoms in chronic back pain. Appl Neuropsychol. 2000;7(2):83-89. [PMID: 10863602] http://dx.doi.org/10.1207/S15324826AN0702 3

19. Schretlen DJ, Testa SM, Winickl JM, Pearlson GD, Gordon B. Frequency and bases of abnormal performance by healthy adults on neuropsychological testing. J Int Neuropsychol Soc. 2008;14(3):436-45. [PMID: 18419842] http://dx.doi.org/10.1017/S1355617708080387

20. International Classification of Functioning, Disability and Health. Geneva (Switzerland): World Health Organization; 2001.

21. International Classification of Impairments, Disabilities and Handicaps: A manual of classification relating to the consequences of disease. Geneva (Switzerland): World Health Organization; 1980. 
22. Pope AM, Tarlov AR. Disability in America: Toward a national agenda for prevention. Washington (DC): National Academy Press; 1991.

23. Brandt EN, Pope AM. Enabling America: Assessing the role of rehabilitation science and engineering. Washington (DC): National Academy Press; 1997.

24. Nagi SZ. An epidemiology of disability among adults in the United States. Milbank Mem Fund Q Health Soc. 1976;54(4):439-67. [PMID: 137366]

http://dx.doi.org/10.2307/3349677

25. Whiteneck G, Dijkers MP. Difficult to measure constructs: Conceptual and methodological issues concerning participation and environmental factors. Arch Phys Med Rehabil. 2009;90(11 Suppl):S22-S35. [PMID: 19892071] http://dx.doi.org/10.1016/j.apmr.2009.06.009

26. Brown M, Dijkers MP, Gordon WA, Ashman T, Charatz H, Cheng Z. Participation objective, participation subjective: A measure of participation combining outsider and insider perspectives. J Head Trauma Rehabil. 2004;19(6):459-81. [PMID: 15602309$]$ http://dx.doi.org/10.1097/00001199-200411000-00004

27. Cella DF, Bonomi AE. Measuring quality of life: 1995 update. Oncology. 1995;9(11 Suppl):47-60. [PMID: 8608056]

28. Campbell A, Converse PE, Rodgers WL. The quality of American life: Perceptions, evaluations, and satisfactions. New York (NY): Russell Sage Foundation; 1976.

29. Patrick DL, Erickson P. What constitutes quality of life? Concepts and dimensions. J Drug Ther Res. 1988;13(5): 152-58.

30. Kahneman D, Diener E, Schwarz N. Well-being: The foundations of hedonic psychology. New York (NY): Russell Sage Foundation; 1999.

31. Hart T, Sherer M, Whyte J, Polansky M, Novack TA. Awareness of behavioral, cognitive, and physical deficits in acute traumatic brain injury. Arch Phys Med Rehabil. 2004;85(9):1450-56. [PMID: 15375815] http://dx.doi.org/10.1016/j.apmr.2004.01.030

32. Hart T, Seignourel PJ, Sherer M. A longitudinal study of awareness of deficit after moderate to severe traumatic brain injury. Neuropsychol Rehabil. 2009;19(2):161-76. [PMID: 18609008] http://dx.doi.org/10.1080/09602010802188393

33. Hart T, Sherer M, Temkin N, Whyte J, Dikmen S, Heinemann A, Bell K. Participant-proxy agreement on objective and subjective aspects of societal participation following traumatic brain injury. J Head Trauma Rehabil. 2010;25(5): 339-48. [PMID: 20042981] http://dx.doi.org/10.1097/HTR.0b013e3181c7e60b

34. Hammel J, Magasi S, Heinemann A, Whiteneck G, Bogner J, Rodriguez E. What does participation mean? An insider perspective from people with disabilities. Disabil Rehabil.
2008;30(19):1445-60. [PMID: 18923977]

http://dx.doi.org/10.1080/09638280701625534

35. Willer B, Ottenbacher KJ, Coad ML. The community integration questionnaire. A comparative examination. Am J Phys Med Rehabil. 1994;73(2):103-11. [PMID: 8148099] http://dx.doi.org/10.1097/00002060-199404000-00006

36. Dijkers M. Measuring the long-term outcomes of traumatic brain injury: A review of the Community Integration Questionnaire. J Head Trauma Rehabil. 1997;12(6):74-91. http://dx.doi.org/10.1097/00001199-199712000-00007

37. Johnston MV, Hall KM. Outcomes evaluation in TBI rehabilitation. Part I: Overview and system principles. Arch Phys Med Rehabil. 1994;75(12 Spec No):SC27-28.

[PMID: 7993176]

38. Sander AM, Fuchs KL, High WM Jr, Hall KM, Kreutzer JS, Rosenthal M. The Community Integration Questionnaire revisited: An assessment of factor structure and validity. Arch Phys Med Rehabil. 1999;80(10):1303-8.

[PMID: 10527092] http://dx.doi.org/10.1016/S0003-9993(99)90034-5

39. Tepper S, Beatty P, DeJong G. Outcomes in traumatic brain injury: Self-report versus report of significant others. Brain Inj. 1996;10(8):575-81. [PMID: 8836514]

http://dx.doi.org/10.1080/026990596124142

40. Hall K, Bushnik T, Lakisic-Kazazic B, Wright J, Cantagallo A. Assessing traumatic brain injury outcome measures for long-term follow-up of community-based individuals. Arch Phys Med Rehabil. 2001;82(3):367-74. [PMID: 11245760] http://dx.doi.org/10.1053/apmr.2001.21525

41. Zhang L, Abreu B, Gonzales V, Seale G, Masel B, Ottenbacher KJ. Comparison of the Community Integration Questionnaire, the Craig Handicap Assessment and Reporting Technique, and the Disability Rating Scale in traumatic brain injury. J Head Trauma Rehabil. 2002;17(6):497-509. [PMID: 12802241] http://dx.doi.org/10.1097/00001199-200212000-00002

42. Hall KM, Johnston MV. Outcomes evaluation in TBI rehabilitation. Part II: Measurement tools for a nationwide data system. Arch Phys Med Rehabil. 1994;75(12 Spec No): SC10-18. [PMID: 7993177]

43. Corrigan JD, Deming R. Psychometric characteristics of the Community Integration Questionnaire: Replication and extension. J Head Trauma Rehabil. 1995;10(4):14-27. http://dx.doi.org/10.1097/00001199-199508000-00005

44. Rosenthal M, Dijkers M, Harrison-Felix C, Nabors N, Witol A, Young ME, Englander JS. Impact of minority status on functional outcome and community integration following traumatic brain injury. J Head Trauma Rehabil. 1996;11(5):40-57. http://dx.doi.org/10.1097/00001199-199610000-00005 
45. Schmidt ME, Garvin LJ, Heinemann AW, Kelly JP. Gender- and age-related role changes following brain injury. J Head Trauma Rehabil. 1995;10(4):14-27. http://dx.doi.org/10.1097/00001199-199508000-00003

46. Sander AM, Pappadis MR, Davis LC, Clark AN, Evans G, Struchen MA, Mazzei DM. Relationship of race/ethnicity and income to community integration following traumatic brain injury: Investigation in a non-rehabilitation trauma sample. NeuroRehabilitation. 2009;24(1):15-27. [PMID: 19208954]

47. Sander AM, Clark A, Pappadis MR. What is community integration anyway?: Defining meaning following traumatic brain injury. J Trauma Rehabil. 2010;25(2):121-27. [PMID: 20134333] http://dx.doi.org/10.1097/HTR.0b013e3181cd1635

48. Sherer M, Roebuck-Spencer T, Davis LC. Outcome assessment in traumatic brain injury clinical trials and prognostic studies. J Head Trauma Rehabil. 2010;25(2):92-98.

[PMID: 20042980] http://dx.doi.org/10.1097/HTR.0b013e3181c9d887

49. Whiteneck GG, Dijkers MP, Heinemann AW, Bogner JA, Bushnik T, Cicerone KD, Corrigan JD, Hart T, Malec JF, Millis SR. Development of the participation assessment with recombined tools-Objective for use with traumatic brain injury. Arch Phys Med Rehabil. 2011;92(4):542-51. [PMID: 21367393] http://dx.doi.org/10.1016/j.apmr.2010.08.002

50. Syllabus detail [Internet]. Traumatic Brain Injury National Data and Statistical Center; 2010 [cited 2010 Apr 11]. Available from: http://www.tbindsc.org/SyllabusDetail.aspx?ID=300

51. Johnston MV, Goverover Y, Dijkers M. Community activities and individuals' satisfaction with them: Quality of life in the first year after traumatic brain injury. Arch Phys Med Rehabil. 2005;86(4):735-45. [PMID: 15827926] http://dx.doi.org/10.1016/j.apmr.2004.10.031

52. Whiteneck GG, Charlifue SW, Gerhart KA, Overholser JD, Richardson GN. Quantifying handicap: A new measure of long-term rehabilitation outcomes. Arch Phys Med Rehabil. 1992;73(6):519-26.

53. Malec J. The Mayo-Portland Adaptability Inventory [Internet]. San Jose (CA): Center for Outcome Measurement in Brain Injury; 2005 [cited 2010 May 13]. Available from: http://www.tbims.org/combi/mpai

54. Resnik L, Plow MA. Measuring participation as defined by the International Classification of Functioning, Disability and Health: An evaluation of existing measures. Arch Phys Med Rehabil. 2009;90(5):856-66. [PMID: 19406308] http://dx.doi.org/10.1016/j.apmr.2008.11.010

55. World Health Organization. ICIDH-2: International Classification of Impairments, Activities, and Participation. A manual of dimensions for disablement and functioning. Geneva (Switzerland): World Health Organization; 1997.
56. Malec JF. The Mayo-Portland Participation Index: A brief and psychometrically sound measure of brain injury outcome. Arch Phys Med Rehabil. 2004;85(12):1989-96.

[PMID: 15605338]

http://dx.doi.org/10.1016/j.apmr.2004.01.032

57. Malec JF. Comparability of Mayo-Portland Adaptability Inventory ratings by staff, significant others and people with acquired brain injury. Brain Inj. 2004;18(6):563-75.

[PMID: 15204337] http://dx.doi.org/10.1080/02699050310001646134

58. Erez AB, Rothschild E, Katz N, Tuchner M, HartmenMaeir A. Executive functioning, awareness, and participation in daily life after mild traumatic brain injury: A preliminary study. Am J Occup Ther. 2009;63(5):634-40.

[PMID: 19785263]

http://dx.doi.org/10.5014/ajot.63.5.634

59. Malec JF, Kragness M, Evans RW, Finlay KL, Kent A, Lezak MD. Further psychometric evaluation and revision of the Mayo-Portland Adaptability Inventory in a national sample. J Head Trauma Rehabil. 2003;18(6):479-92.

[PMID: 14707878 http://dx.doi.org/10.1097/00001199-200311000-00002

60. Malec JF, Thompson JM. Relationship of the Mayo-Portland Adaptability Inventory to functional outcome and cognitive performance measures. J Head Trauma Rehabil. 1994;9(4): 1-15. http://dx.doi.org/10.1097/00001199-199412000-00003

61. Bohac DL, Malec JF, Moessner AM. Factor analysis of the Mayo-Portland Adaptability Inventory: Structure and validity. Brain Inj. 1997;11(7):469-82. [PMID: 9210984]

62. Malec JF. Impact of comprehensive day treatment on societal participation for persons with acquired brain injury. Arch Phys Med Rehabil. 2001;82(7):885-95.

[PMID: 11441373]

http://dx.doi.org/10.1053/apmr.2001.23895

63. Malec JF, Buffington AL, Moessner AM, Degiorgio L. A medical/vocational case coordination system for persons with brain injury: An evaluation of employment outcomes. Arch Phys Med Rehabil. 2000;81(8):1007-15.

[PMID: 10943747]

http://dx.doi.org/10.1053/apmr.2000.6980

64. Malec J, Degiorgio L. Characteristics of successful and unsuccessful completers of 3 postacute brain injury rehabilitation pathways. Arch Phys Med Rehabil. 2002;88(12): 1759-64. [PMID: 12474183] http://dx.doi.org/10.1053/apmr.2002.36072

65. U.S. Department of Education. NIDRR Long-range plan for fiscal years 2005-09: Executive summary [Internet]. Washington (DC): U.S. Department of Education, Office of Special Education and Rehabilitative Services, National Institute on Disability and Rehabilitation Research; 2007 [updated 2007 Mar; cited 2010 Jun 20]. Available from: 
http://www.ncddr.org/new/announcements/lrp/fy20052009/exec-summ.html

66. Carlozzi NE, Tulsky DS, Kisala P. Traumatic brain injury (TBI) patient reported outcome measure: Identification of issues relevant to individuals with TBI. Arch Phys Med Rehabil. 2011;92(10 Suppl 1):S52-S60. [PMID: 21958923] http://dx.doi.org/10.1016/j.apmr.2010.12.046

67. Steinfield C, Ellison NB, Lampe C. Social capital, selfesteem, and use of online social network sites: A longitudinal analysis. J App Develop Psychol. 2008;29:434-45. http://dx.doi.org/10.1016/j.appdev.2008.07.002

68. Park N, Kee KF, Valenzuela S. Being immersed in social networking environment: Facebook groups, uses and gratifications, and social outcomes. Cyberpsychol Behav. 2009; 12(6):729-33. [PMID: 19619037] http://dx.doi.org/10.1089/cpb.2009.0003

69. U.S. Department of Health and Human Services FDA Center for Drug Evaluation and Research; U.S. Department of Health and Human Services FDA Center for Biologics Evaluation and Research; U.S. Department of Health and Human Services FDA Center for Devices and Radiological Health. Guidance for industry: Patient-reported outcome measures: Use in medical product development to support labeling claims: Draft guidance. Health Qual Life Outcomes. 2006;4:79. [PMID: 17034633] http://dx.doi.org/10.1186/1477-7525-4-79

70. DeWalt D, Rothrock N, Yount S, Stone AA; PROMIS qualitative item review. Evaluation of item candidates: The PROMIS qualitative item review. Med Care. 2007;45(5 Suppl 1):S12-21. [PMID: 17443114] http://dx.doi.org/10.1097/01.mlr.0000254567.79743.e2

71. Schwartz S, Sudman S. Answering questions: Methodology for determining cognitive and communicative processes in survey research. San Francisco (CA): Josey-Bass; 1996.

72. Bond TG, Fox CM. Applying the Rasch model. Mahwah (NJ): Lawrence Erlbaum Associates; 2001.
73. Linacre JM, Heinemann AW, Wright BD, Granger CV, Hamilton BB. The structure and stability of the Functional Independence Measure. Arch Phys Med Rehabil. 1994; 75(2):127-32. [PMID: 8311667]

74. Gandek B, Sinclair SJ, Jette AM, Ware JE Jr. Development and initial psychometric evaluation of the Participation Measure for Post-Acute Care (PM-PAC). Am J Phys Med Rehabil. 2007;86(1):57-71. [PMID: 17033591] http://dx.doi.org/10.1097/01.phm.0000233200.43822.21

75. Bode RK, Hahn EA, DeVellis R, Cella D; Patient-Reported Outcomes Measurement Information System Social Domain Working Group. Measuring participation: The patientreported outcomes measurement information system experience. Arch Phys Med Rehabil. 2010;91(9 Suppl):S60-65. [PMID: 20801282] http://dx.doi.org/10.1016/j.apmr.2009.10.035

76. Seekins T, Ipsen C, Arnold NL. Using Ecological Momentary Assessment to measure participation: A preliminary study. Rehabil Psychol. 2007;52(3):319-30.

http://dx.doi.org/10.1037/0090-5550.52.3.319

Submitted for publication July 15, 2010. Accepted in revised form March 2, 2011.

This article and any supplementary material should be cited as follows:

Stiers W, Carlozzi N, Cernich A, Velozo C, Pape T, Hart T, Gulliver S, Rogers M, Villarreal E, Gordon S, Gordon W, Whiteneck G. Measurement of social participation outcomes in rehabilitation of veterans with traumatic brain injury. J Rehabil Res Dev. 2012;49(1):139-54.

http://dx.doi.org/10.1682/JRRD.2010.07.0131




